\title{
Los efectos del turismo en las culturas indígenas de América Latina
}

\author{
Xerardo Pereiro \\ Universidade de Trás-os-Montes e Alto Douro \\ xperez@utad.pt
}

Recibido: 5 de noviembre de 2011

Aceptado: 3 de diciembre de 2012

\begin{abstract}
RESUMEN
En nuestro texto analizamos las perspectivas de los efectos del turismo sobre las comunidades indígenas de América Latina o Abya Yala. Para ello partimos de sus debates académicos y de nuestra experiencia de investigación con el turismo indígena kuna (Panamá). Ello puede contribuir a una mejor comprensión de un nuevo tiempo en el que los turistas buscan cada vez más al otro y una relación más intensa con la cultura y la naturaleza para repensar su lugar en el mundo. En el texto, y por motivos de espacio, no analizamos los efectos del turismo indígena sobre los turistas y otros agentes sociales que intervienen en el sistema turístico.
\end{abstract}

Palabras clave: antropología, turismo indígena, América Latina

\section{The Effects of Tourism on the Indigenous Cultures of Latin America}

\begin{abstract}
In my report, I have analysed the prospects of the effects of tourism on indigenous communities in Latin America or Abya Yala. In order to do this, I started from their academic discussions and my research experience with the Kuna indigenous tourism (Panama). This can contribute to a better understanding of a new era in which tourists are increasingly seeking a different and stronger relationship with culture and nature to rethink their place in the world. In this report, and for reasons of space, I didn't analyse the effects of indigenous tourism on tourists and other social actors involved in the tourism system.
\end{abstract}

Key words: Anthropology, indigenous tourism, Latin America.

Sumario: 1. Introducción. 2. Los efectos del turismo en comunidades indígenas de América Latina. 3. Conclusiones. 4. Referencias bibliográficas.

\section{Introducción}

\subsection{Antropología, turismo e impactos}

Si por algo se caracteriza tradicionalmente la antropología del turismo es por haber centrado sus investigaciones en los impactos de la actividad turística en las comunidades receptoras (Boissevain 1996, 2005; Gmelch 2003; Pereiro 2009), pero muy pocos trabajos antropológicos se han centrado en los efectos del turismo sobre los propios turistas (Harrison 2003).

Tal como ha indicado Joel B. Salazar (2006: 99 y ss.), la antropología del turismo en países subdesarrollados se ha centrado en responder a cuestiones relacionadas con la dinámica e impactos del contacto intercultural entre turistas y nativos, la representación de la cultura en los escenarios turísticos, los estereotipos étnicos construidos y manipulados por el turismo, el cambio de los valores culturales una vez mercantilizados y las relaciones de poder en el contexto del turismo internacional. 
Uno de los primeros teóricos en reflexionar sobre los efectos del turismo fue la antropóloga Valene Smith (1977). Podemos definir los trabajos coordinados por Valene Smith en 1977 como un conjunto de textos críticos sobre los efectos negativos del turismo y, especialmente, del turismo étnico sobre las comunidades receptoras. En la misma década, Enmanuel De Kadt afirma que «el turismo es una plaga para los países en vías de desarrollo» (De Kadt 1979: 11). El conjunto de trabajos editados por De Kadt llamarán la atención sobre la sustitución de las actividades primarias por el turismo, la creciente dependencia del mismo por parte de las comunidades receptoras, la acentuación de las divisiones sociales entre quien se beneficia y no de la actividad turística, la especulación del suelo, la inflación, la expropiación territorial de zonas indígenas y la especulación inmobiliaria, entre otros aspectos críticos.

Hasta entonces, y sobre todo en la década de los 60, el turismo había sido considerado desde una perspectiva economicista como un impulsor de crecimiento económico y se prestaba atención a sus efectos sociales, culturales y medioambientales. Por ello, los dos trabajos citados anteriormente denotan una preocupación por un mal desarrollo del turismo si éste no es planeado, bien pensado y gestionado.

Valene Smith coordinará y publicará una revisión de los autores de/a sus textos publicados en 1977, en la que presenta un panorama un poco más optimista (Smith 1989), pero aún así algunos autores mantuvieron en los años 90 una perspectiva negativa sobre los efectos del turismo étnico. En la misma obra y en la misma línea, Davyd Greenwood (1992) reforzaba el modelo de mercantilización y comercialización de la cultura como algo negativo para la población receptora y que ya había elaborado en su interpretación de la fiesta del Alarde (Hondarribia, País Vasco) de 1977. Ese modelo sería criticado por Erick Cohen (1988) por su excesiva sobregeneralización y porque, según él, la mercantilización de la cultura no es siempre negativa, sino que puede llevar a la recuperación de tradiciones culturales y traer efectos positivos sobre la población receptora.

A pesar de ello, algunos trabajos pioneros como los de Valene Smith (1977 y 1989) ya apuntaban la diversidad de reacciones comunitarias frente al turismo, por ejemplo, cuando estudia dos comunidades inuit (King Island y Shishmaref) que adoptan posiciones completamente diferentes frente al turismo. Por un lado, la comunidad de King Island rechazaba el turismo y apostaba por la minería del oro y por los astilleros. Por otro lado, Shishmaref (en el estrecho de Bering) abrazaba el turismo como una apuesta de desarrollo. Es un ejemplo de cómo dentro de un mismo universo cultural étnico pueden coexistir respuestas y reacciones grupales diferentes en función de oportunidades, ideologías e intereses.

Como observamos, tradicionalmente los antropólogos hemos estudiado los efectos del turismo y los turistas sobre las comunidades receptoras. Ello ha dibujado un panorama crítico sobre el turismo, pero también ha incidido, tal vez demasiado, sobre tres aspectos: a) el turismo como el más importante motor de cambios sociales y culturales -a veces el único-; b) las comunidades receptoras pasivas que no participan activamente en el desarrollo turístico; c) el turismo como una fuerza externa que actúa desde fuera e impacta sobre los receptores, pero menos sobre los turistas.

Hoy en día, la perspectiva antropológica sabe que el turismo no es el único motor de los cambios, y ni siquiera el más importante en muchos casos (Santana 1997: 
92; Barreto 2007: 39; Prats y Santana 2011: 4). Además, el turismo no se desarrolla siempre desde fuera hacia dentro, sino que la realidad empírica etnografiada suele demostrar más bien lo contrario, es decir, la relación entre lo local y lo global y la participación activa de los grupos étnicos y las localidades en el desarrollo turístico. Frente al modelo de aculturación y el modelo de impactos causa-efecto y exteriorinterior, Margarita Barreto (2007: 53 y ss.) propone la adopción de nuevos modelos como la reflexividad, el dialogismo, el cosmopolitismo, el hibridismo cultural y el modelo de los límites aceptables de cambio. El antropólogo Noel Salazar (2006: 118) también converge hacia esa perspectiva:

«... no debemos olvidar que el turismo es sólo uno de los varios flujos globales con influencia para afectar de manera importante las actitudes y valores de las personas en todas las sociedades. Otros incluyen los medios de masas globalizados, la educación y la urbanización.»

\subsection{Comprender el turismo indígena}

El turismo al que nos estamos refiriendo se denomina de muchas formas: turismo étnico, etnoturismo, turismo indígena, etnoecoturismo, turismo aborigen, etc. Por ello, una de sus primeras características es su imprecisión y su ambigüedad. Este tipo o modo de hacer turismo hay que vincularlo con la creencia y con la mirada turística occidental de que son los pueblos indígenas los preservadores de los valores humanos más auténticos y de que ellos están más próximos a la naturaleza y a un medio ambiente ya muy devastado en Occidente. Esta es una forma de nostalgia que ha servido en muchos casos para generar presencias turísticas, pero también para mercantilizar y volver más exótica la cultura indígena.

Al mismo tiempo, pensamos que hay que vincularlo con los movimientos sociales indigenistas y los movimientos sociales de turismos alternativos y altermundistas ${ }^{1}$. Dentro de estos movimientos, también hay que considerar las diferentes construcciones de lo indígena en cada país de América Latina (ej.: Perú, Guatemala, Panamá, México, Bolivia, Brasil,...) y cómo ellas han condicionado los desarrollos de los turismos indígenas, que en algunos casos se orientan solamente a un turismo extranjero atraído por el exotismo indígena y no integran a la población «nacional», pues esta sigue viendo a los indígenas como pobres, inferiores y causantes de un cierto atraso.

Pero como objeto de investigación, el turismo indígena se ha abierto como campo importante desde los años 90 (Mercer 1995; Butler y Hinch 1996; Picard y Wood 1997; Moscardo y Pearce 1999; Zeppel 2007: 310). Zeppel recopiló numerosas referencias bibliográficas (1999) para el caso australiano y la Canadian Tourism Commission (1997) para el caso canadiense. Más recientemente, un trabajo de Diana Kutzner et al. (2007) reúne 323 referencias bibliográficas sobre turismo indígena, y en la revista Bulletin of Latin American Research encontramos 41 artículos relativos a «indigenous tourism» en toda su historia. C. Michael Hall y otros (2007: 37) muestran cómo las palabras «etnia» y «grupos étnicos» aparecen 57 veces en las palabras

1 Ver debates del Foro Social de Portalegre 2002 en www.ivt-rj.net/destaques/forum/index.htm 
clave de los índices del 2002 de la prestigiosa editora de turismo y ciencias sociales CABI, además esas palabras son de las más citadas en ese índice desde el año 1990, junto con historia, sostenibilidad y herencia cultural.

En la década de 1990 el turismo indígena fue definido como el conjunto de experiencias de primera mano con culturas indígenas (Harron y Weiler 1992), una forma de colección cultural (Volkman 1990) y también como un campo de relaciones coétnicas (Van den Berghe 1980, 1994a) caracterizado por la atracción del otro y su cultura, lo diferente y el «exotismo étnico», es decir, lo nativo como objeto de curiosidad «turistado». En esa época, la antropóloga estadounidense Valene Smith lo definió así:

«El turismo indígena... es un segmento de la industria de visitas que implica directamente a pueblos nativos cuya etnicidad constituye una atracción turística... El turismo indígena integra cuatro elementos interrelacionados: el asentamiento geográfico (hábitat), las tradiciones etnográficas (herencia cultural), los efectos de la aculturación (historia) y las artesanías comercializables» (Smith 1996: 283 y 287, traducción nuestra).

El británico Richard Butler y el canadiense Tom Hinch se muestran muy favorables a la comercialización del turismo indígena, y definirán este como:

«Un turismo en el que los propios indígenas participan con empresas propias o a través de la comercialización de su cultura, considerando su aspecto eminentemente turístico y la demanda. El turismo indígena incluye ofertas preparadas por los propios nativos, con temas indígenas que son el núcleo de dichas ofertas» (Butler y Hinch 1996, traducción nuestra).

Desde la perspectiva de estos autores citados (Smith 1996; Butler y Hinch 1996), el turismo indígena es considerado más una oferta de un producto que una forma diferente de hacer turismo, es decir, una relación comercial entre productores y consumidores (turistas) mediados por una serie de productos como son el hábitat, el patrimonio cultural, la historia social y la artesanía de los indígenas.

Desde otra óptica y en esa misma época, Edward Bruner denomina a esa búsqueda de tipismo indígena (1995: 224) como enmascaramiento de las vidas de los indígenas para parecer más atractivos a los ojos del visitante y satisfacer las expectativas del turista. Las culturas «tradicionales» e indígenas que los antropólogos hemos descrito en el pasado, nos dice Bruner (1995: 232), son ahora buscadas por los turistas, aunque paradójicamente esas culturas hayan cambiado y ya no sean lo que eran.

En esa década de 1990 la clasificación tipológica llevaba a autores como Valene Smith y Peter Van den Berghe a conceptualizar el turismo étnico como algo diferente del turismo cultural; sin embargo, Greg Richards (1996) afirmará que el turismo étnico es parte del turismo cultural. Sin entrar a fondo en ese debate tipológico, que no nos parece tan importante (solamente para efectos de mercadeo), en la década de 2000 encontramos nuevas tentativas de definición:

«El turismo étnico puede definirse como una forma de turismo en la cual la principal motivación del turista implica un deseo de tener experiencias e interactuar con pueblos étnicos exóticos» (Oakes 2000: 204, traducción nuestra). 
Esta última definición se centra en la perspectiva del turismo y sus motivos y, de acuerdo con ella, el exotismo es la primera atracción para el turista, que pretende ver modos de vida diferentes al suyo y reconstruir así los sentidos de la identidad, del lugar y de la tradición (Oakes 2000: 204-205).

El antropólogo brasileño Rodrigo de Azeredo Grünewald (2003) diferenciará entre dos perspectivas. La primera es aquella que se centra en el objeto de turismo, que en este caso es un nativo o indígena. La segunda atiende más a lo que el turismo/ turista mira o encuentra durante su visita. Pero en las dos, y según este autor, para que exista turismo indígena debe existir un movimiento social que construya una etnicidad específica para mostrarla en la esfera turística. Según este autor, y siguiendo a Comaroff (1992: 57), la etnicidad hay que entenderla como un bricolaje modelado por la cultura.

Por esas fechas, la OMT (Organización Mundial del Turismo) definirá el turismo indígena como una segmentación del turismo cultural en relación a las ideas de etnicidad como motivación de la visita. Según esta organización, este turismo, al que ellos califican como étnico, sería aquel orientado a «las tradiciones y estilo de vida de un grupo y utilizado principalmente para destacar el turismo en las comunidades o enclaves específicos en proceso de desarrollo» (OMT 2003: 168, traducción nuestra).

Más recientemente, dos autores neozelandeses, Chris Ryan y Michel Aicken, han editado una obra colectiva sobre turismo indígena de gran impacto en la investigación turística (Ryan y Aicken 2005). En esta obra se reúnen casos de estudios en Oceanía, Este asiático, Canadá y Escandinavia. Por lo tanto, hay una ausencia de ejemplos de América Latina, pero también de autores propiamente indígenas; no obstante, sus perspectivas teóricas son muy sugerentes. Ya en la introducción, Chris Ryan afirma que el turismo es un factor de creación de imágenes estereotipadas de los pueblos indígenas (Ryan 2005a: 1-15). Ryan y Jeremy Huyton (2005: 51 y ss.), afirman que para los visitantes no es tan importante la experiencia interactiva como el comprar arte y artesanía.

En otro texto de Chris Ryan (Ryan 2005b: 69 y ss.), éste destaca la paradoja de que el turismo, como satisfacción del deseo de nuevas oportunidades económicas para las zonas indígenas, choca con el esfuerzo indígena por sustentar una cultura que está en vías de mercantilización. Es decir, el mercantilismo de la cultura indígena parece inevitable si se quiere obtener beneficio del turismo. Nos preguntamos si esto no debe tener sus límites éticos o, como se cuestiona en las conclusiones de la obra citada: ¿cómo no perder las tradiciones y ganar beneficios económicos del turismo? En resumen, esta publicación se centra en analizar cómo los grupos indígenas crean y recrean sus identidades por medio del turismo, centrándose en que los pueblos indígenas son un factor de diferenciación turística en un contexto de globalización.

En el turismo indígena, la etnicidad indígena (Vermeulen y Govers 2003) se reconstruye para los turistas (MacCannell 1984; MacCannell 1992; Grünewald 2003) y para la visión y el consumo mercantil de la cultura indígena, transfiriendo las identidades y los lugares étnicos al mercado turístico global. Ello puede derivar en reinvención, preservación y recreación de atributos étnicos, pero suele producirse a costa de perder privacidad y experimentar un cierto sentimiento de invasión y amenaza. Por lo tanto, la investigación sobre el turismo indígena nos obliga a ver lo indígena y 
la etnicidad como categorías maleables, flexibles, dinámicas y estratégicas, sujetas a negociaciones y renegociaciones constantes.

La etnicidad hay que entenderla aquí de tres maneras (Vermeulen y Govers 2003: 9): a) como una forma de organización social de la diferencia; b) como una frontera, generalmente simbólica, entre grupos y no estrictamente como un contenido cultural diferente; c) como una adscripción o clasificación de terceros y también como una autoadscripción. La etnicidad, como tipo de identidad social, es una creencia compartida y una consciencia de la diferencia, pero también un grupo de interés y una ideología de la ascendencia, substancia o historia común (Vermeulen y Govers 2003: 11-12).

La etnicidad es también una narrativa que se puede observar en el campo del turismo como expresión política de las identidades en construcción permanente, por ser ellas siempre incompletas. Y en el campo del turismo, la etnicidad es reconstruida por el turismo, ello sucede en parte por lo que Renato Rosaldo (1989: 93) define como «nostalgia imperialista», es decir, una forma que hace que el dominio colonial y neocolonial parezcan inocentes y puros.

La nostalgia imperialista es un lamentarse por lo que antes hemos destruido. Tras alterar la forma de vida de los indígenas, los occidentales sienten culpa por lo que han hecho, se arrepienten y desean que las cosas sean como antes, queriendo convertir las zonas indígenas en una especie de zoológico con animales congelados. Es lo que pone de manifiesto Cannibal Tours, el documental de Dennis O'Rourke (1988) rodado en Papúa Nueva Guinea y que narra las vicisitudes de un grupo de turistas occidentales que visita comunidades indígenas.

Desde una perspectiva semejante, autores como Dennison Nash (1992) o Duccio Canestrini (2009) han interpretado el turismo como una forma de imperialismo y neocolonialismo. Y en esta línea más crítica, Alison Johnston (2006) publica un trabajo que cuestiona el turismo en zonas indígenas. Esta autora señala el ecoturismo en zonas indígenas como una práctica turística que se presenta a las clases medias occidentales como solución para el sentido de pérdida de patrimonios culturales y naturales que ellas tienen.

Si bien el ecoturismo, que representa un 5\% del turismo internacional, es considerado una forma benigna de turismo, un apoyo de las culturas indígenas y un creador de conexiones espirituales con la naturaleza, para Johnston el ecoturismo en contextos indígenas está asociado a choques entre el medio ambiente, las multinacionales y los intereses culturales indígenas.

Según esta autora, el ecoturismo nace en los años 80 vinculado a la moda de lo sostenible, para luego en los años 90 presentarse como una alternativa popular a la explotación económica destructiva. Sin embargo, nos dice esta autora que lo que ha sucedido es una pérdida de los derechos indígenas y de sus patrimonios culturales, la conversión en mercancías de individuos y comunidades indígenas, la pérdida de cultura e identidad de los pueblos indígenas y la continuidad de las políticas y prácticas coloniales.

Frente al conjunto de trabajos reunidos por Ryan y Aicken (2005), para quienes la posición del investigador puede ser la de diseñador del producto turístico o la de investigador de las expectativas indígenas, sus modelos de cambio y cómo manejarlos, Johnston (2006) se muestra muy crítica con la mercantilización de la cultura indígena y su medio ambiente, y no considera al turismo como algo inevitable a lo que hay que 
ajustarse, como dan a entender los trabajos de Ryan y Aicken. Por ello, Johnston se pregunta si lo sagrado y lo espiritual de los indígenas se debe vender a través del turismo.

Lo cierto es que el turismo es una fuerza poderosa que fomenta el contacto entre culturas y que crea un nuevo marco de relaciones interétnicas. El turismo atraviesa fronteras, divulga imágenes pre-existentes, las re-crea y también genera nuevas imágenes sobre los otros, incidiendo en la redefinición de límites culturales y creando nuevas formas culturales que se mercantilizan (Hernández 2006: 24). Esta mercantilización hay que ponerla en relación con los nuevos turismos sostenibles y responsables, los proyectos de desarrollo turístico para combatir la pobreza (estrategia metodológica del «pro-poor tourism») y la cooperación internacional (Gascón 2009).

Algunos autores están ampliando la definición conceptual de turismo indígena, bajo el paraguas de turismo étnico, a grupos de campesinos que desarrollan turismo en un espacio rural, al turismo de raíces o de nostalgia (regreso a los orígenes), al turismo de herencia cultural y al turismo de interculturalidad (Costa 2006; Cavaco 2009). Estas nuevas orientaciones llevan a poner en cuestión el turismo étnico como turismo indígena y a estirar éste hasta el punto de intimar con otros tipos y formas de hacer turismo. La consecuencia es la eliminación de las fronteras conceptuales del turismo indígena, del turismo étnico y la redefinición de lo étnico y lo indígena.

Desde nuestra perspectiva, los turismos étnicos, es decir, las diversas formas del turismo étnico, incluido el turismo indígena, pueden encuadrarse en lo que Smith y Eadington (1992: 3) denominan turismos alternativos, es decir, «aquellas formas de turismo que son consistentes con los valores naturales, sociales y comunitarios, y que permiten a anfitriones e invitados gozar de una interacción positiva y valiosa de experiencias compartidas». Según Margarita Barretto, esas alternativas lo son a los productos turísticos tradicionales de sol y playa. Para esta autora, el turismo étnico es una forma particular reciente de turismo cultural, en el cual «el atractivo principal es la forma de vida de determinados grupos humanos, diferenciados por raza, religión, región de procedencia y otras características comunes» (Barretto 2005: 40). Así, los grupos étnicos utilizan su diferencial étnico como atractivo turístico. Pero según Barretto (2005: 50-51) hay dos formas de desarrollar el turismo étnico:

1. Los turismos étnicos que nacen del más puro interés comercial y que reducen el turismo a negocio. Este tipo es un turismo no planificado, sin consentimiento expreso de la comunidad y que lleva a la creación de zoológicos humanos.

2. Los turismos étnicos que son resultado de proyectos comunitarios de revitalización cultural y afirmación de las identidades étnicas. En ellos los grupos humanos se autodeterminan para mostrar a los turistas de forma selectiva algunos elementos de su cultura. En este tipo de desarrollo del turismo étnico, la consulta, las políticas públicas y las funciones de regulación son fundamentales a la hora de desarrollar las actividades turísticas.

Esta segunda forma va al encuentro del turismo comunitario, pero tampoco podemos dejar de lado que muchas veces el interés económico parte de las mismas comunidades y se organiza con el poder de sus identidades colectivas, es decir, que para ellos el turismo es «un negocio» o «el negocio», una oportunidad de supervivencia en unos casos y reproducción o afirmación indigenista en otros. 
En síntesis: creemos que podemos concluir este apartado siguiendo la perspectiva barthiana (Barth 1969, 2003), de que el turismo indígena es una forma de organización social de la diferencia más que un atributo cultural, es más un elemento del proceso de afirmación étnica y no solamente una señal diacrítica de su identidad construida sobre relaciones de semejanza y diferencia.

\section{Los efectos del turismo en comunidades indígenas de América Latina}

«Lo que más nos duele a los indios es que nuestras costumbres se consideren bellas, pero es como si las personas que las practican no existieran» (Rigoberta Menchu, Premio Nobel de la Paz, citado en Mastny 2003: 28).

En la literatura científica internacional sobre turismo indígena se ha teorizado mucho a partir de casos y experiencias de África, Asia, Canadá, Nueva Zelanda, Australia y Estados Unidos, pero menos sobre la experiencia latinoamericana. Ello es debido, en parte, a cuestiones de relación entre conocimiento y poder, tales como: a) el uso del inglés como lengua dominante en los estudios turísticos (Mowforth et al. 2008), lo que provoca que las publicaciones en español y en portugués, lenguas dominantes en América Latina, hayan tenido menos impacto en la literatura científica internacional; b) el desarrollo más reciente del turismo indígena en América Latina; c) el interés poscolonial de muchos investigadores de trabajar en ex colonias.

Si analizamos la literatura científica del turismo indígena en América Latina, encontramos tres tipos de análisis interpretativos: (1) el de aquellos que responden a una visión optimista o positiva del turismo; (2) el de quienes responden a una visión negativista o crítica del turismo, (3) el de quienes construyen una visión de adaptación creativa a los cambios producidos por el turismo.

\subsection{La visión optimista o positiva del turismo indígena}

En la década de los 90, autores como Pitchford (1995) presentan un panorama optimista del turismo étnico e indígena, afirmando que puede revitalizar artes, promover la creatividad cultural y producir una plataforma para la presentación positiva de tales grupos humanos. En esa misma línea, la postura de Margarita Barretto (2007) es bastante ilustrativa, al defender la idea de que el turismo no es el único motor de cambios entre las comunidades receptoras $\mathrm{y}$, a veces, los cambios que produce no son tan negativos. En este sentido, Moscardo y Pearce (1999: 149) diferencian dos tipos de situaciones de contacto en el turismo indígena. Por un lado, la situación de contacto visual de artesanías, artes o arquitecturas; por otro, la situación de representaciones interactivas como las danzas, las «living history» y otras. En función de este tipo de situaciones de contacto, piensan que los impactos del turismo indígena son diferentes, pues los escenarios y los actores en juego son diferentes.

Cuando hablamos de efectos positivos del turismo indígena, la literatura científica destaca el conocer gente diferente, el intercambio cultural y el servir de estímulo para la producción artesanal (Getino 1991: 123). El turismo en comunidades indígenas 
puede crear un mayor respeto por estas, ayudando a mantener o revitalizar lenguas o tradiciones (Mastny 2003: 28) y trayendo beneficios económicos que, según muchos autores, combaten la pobreza extrema.

Ejemplos de esta visión positiva son Ingles (2002) para el caso de la Amazonía peruana, Maldonado (2006) sobre la red «redturs» ${ }^{2}$, Espinosa (2010) sobre la red de turismo comunitario «Saraguro Rikuy» en Ecuador ${ }^{3}$, o Chernela (2011) para el ecoturismo kuna (Panamá), según los cuales el turismo revitaliza las comunidades indígenas, les da rendimientos económicos y les abre una puerta para mostrar su identidad cultural al mundo. Otro ejemplo es el proyecto «Mundo Maya» (Morales y Marías 2007: 131), una iniciativa de cooperación turística regional en la que participa México, Guatemala, Belice, El Salvador y Honduras. En el proyecto las mujeres fabrican blusas y otros productos con motivos indígenas para los visitantes, al mismo tiempo que venden maíz y chile.

Los cofán (Amazonas) y los kuaorni de Ecuador han organizado activamente su turismo, creando alojamientos y tiendas de artesanía que generan $500 \$$ por residente y año (Mastny 2003: 29 y 46). Los huaorani de Ecuador desarrollan un turismo comunitario con distribución equitativa del dinero, ganando el doble que trabajando para una empresa petrolífera (Mastny 2003: 46). Ellos, los huaroni, solamente aceptan un grupo de visitantes durante un periodo de entre dos y seis días al mes, pues temen que el turismo destruya su modo de vida basado en la caza y en la recolección. Guían a sus huéspedes por la selva, les enseñan ecología y etnobotánica, además de la artesanía local. Han sido asesorados por la Tropic Ecological Adventures, touroperador con gran experiencia en trabajo con comunidades indígenas y que, al mismo tiempo, ha dado a conocer su conflicto con una empresa petrolera. Su proyecto recibió el premio al mejor proyecto ecoturístico de la Exposición de Turismo de Berlín, en 1998 (Blangy 1999).

Otro buen ejemplo es la agencia de viajes Wanamei Expediciones, con sede en Cuzco, propiedad de ocho comunidades indígenas de la selva amazónica. Organiza turismo responsable por los territorios tradicionales de los harakmbut, yine y matsiguenga, por el río Madre de Dios.

Según Fander Falconí y Juan Ponce (2007), en Capirona (Ecuador), existe una comunidad indígena quichua que lleva a cabo desde el año 1989 un modelo de desarrollo basado en el ecoturismo comunitario. La comunidad está integrada por 113 personas, y el proyecto recibe sobre todo a europeos interesados en conocer su cultura y biodiversidad, pero también en tener una aventura diferente en el Amazonas. A diferencia de Capirona, la comunidad próxima de Ongota, formada por unas 156 personas (quichuas) ha optado por adoptar un modelo de desarrollo diferente, trabajan como asalariados en una mina y dependen más de la vecina pequeña ciudad de Tena (40.000 habitantes), a 45 minutos en autobús. El resultado ha sido una mayor exclusión y desigualdad, contaminación de sus ríos y problemas con sus recursos naturales. La comunidad de Capirona está integrada en la Red Indígena de Comunidades del Alto Napo para la Convivencia Intercultural y Ecoturismo (RICANCIE), que desde 1993 desarrollan ecoturismo comunitario en nueve comunidades quichuas,

\footnotetext{
2 Ver http://www.redturs.org

3 Ver http://www.turismosaraguro.com
} 
practicando un «turismo organizado» frente a lo que los autores citados denominan «turismo agresivo» ${ }^{4}$. Otros ejemplos se pueden ver en la web de REDTURS 5 , una red de iniciativas turísticas protagonizadas por indígenas y campesinos con base local comunitaria y con gran énfasis en el desarrollo de turismos comunitarios.

\subsection{La visión negativista del turismo indígena}

Una segunda perspectiva es la que se muestra más crítica con los efectos del turismo en las poblaciones receptoras (Gascón Gutiérrez 2005; Gascón y Cañada 2005; Buades 2006; Johnston 2006; Vigna 2006), y es foco de atención central de la mayoría de los trabajos sobre el turismo indígena en América Latina. Son muchos los ejemplos que siguen esta línea, pero nos gustaría destacar algunos casos ejemplarizantes, muy significativos y de gran impacto en la academia.

En este sentido, algunos números de la revista Cultural Survival Quaterly de 1982 y 1990 han alertado sobre las consecuencias negativas del turismo sobre los grupos indígenas. En este contexto hay que destacar el trabajo del antropólogo Pierre Van den Berghe (1994b), quien analiza el caso de San Cristóbal (Chiapas, México) y los cambios producidos en y por el turismo. Si en los años 60 la comunidad recibía a unos pocos mochileros, en los años 80 pasó a recibir cientos de turistas que buscaban lo étnicamente exótico, intacto, «primitivo» y «auténtico», generando una alteración radical en los modos de vivir indígenas.

Pierre L. Van Den Berghe (1994b: 10) definirá el turismo indígena, que él entiende como étnico, de la forma siguiente: «El turismo étnico representa la última ola de expansión del capitalismo explotador para la más remota periferia del sistema mundial». Para este autor, el turismo sería como una especie de reconquista occidental y los turistas unos neoconquistadores, utilizando los conceptos de Renato Athias Monteiro (2008). Entre los efectos del turismo tradicionalmente considerados como negativos, y si seguimos a Octavio Getino (1991: 123-124), destacan:

1. Conflictos intrafamiliares (divorcios, etc.).

2. Transformación de los rituales, convertidos en espectáculos teatrales para turistas extranjeros.

3. Congelación de la cultura y del exotismo, musealización de la cultura para consumo del visitante.

4. Inmovilización de los procesos culturales.

5. Deterioro de los recursos naturales por falta de control.

Para Lisa Mastny (2003), los efectos negativos del turismo sobre comunidades indígenas son en líneas generales:

1. La conversión de los indígenas en «atracciones caracterizadas».

2. Las pocas oportunidades de aceptar o rechazar los cambios que trae el turismo.

3. Reducir las culturas a fotografías instantáneas de folletos.

4. Considerar a los residentes locales como rarezas y no como personas.

\footnotetext{
${ }^{4}$ Esta red tiene una web muy interesante: $\mathrm{http} / / /$ ricancie.nativeweb.org/html/quienes.html

5 Ver http://www.redturs.org
} 
5. El uso excesivo y el deterioro de sus principales atractivos e instalaciones.

6. El deterioro de la calidad ambiental.

7. La corrupción del concepto de ecoturismo como simple viaje a la naturaleza.

Muchos de estos efectos se pueden sintetizar en la idea de que el desarrollo del turismo indígena suele acentuar mucho los aspectos culturales tradicionales y nativistas, pero no los contemporáneos, creando así una imagen idealizada de sus modos de vivir, estatizando los mismos y utilizando estereotipos ligados a la ideología del «buen salvaje».

Uno de los analistas más crítico y más certero con el desarrollo turístico en América Latina, Ernest Cañada (2010: 11), nos dice que es necesario cuestionar el discurso oficial que atribuye al turismo un papel destacado en la reducción de la pobreza. Según este autor, se ha producido un cambio económico estructural en toda Centroamérica, según el cual se ha pasado de la agroexportación tradicional (algodón, banano, azúcar, café y carne) a un modelo económico más complejo con predominio de las remesas, las exportaciones agrícolas, la maquila y el turismo.

De acuerdo con Ernest Cañada, el mayor peso del turismo ha venido precedido de una crisis en lo agropecuario y ha derivado en lo que él denomina «turismo sin desarrollo» y «modelo turístico insostenible» (Cañada 2010: 12), debido a que los gobiernos apenas han considerado al sector privado y al capital extranjero como claves en la actividad turística, concentrando su inversión en el modelo de sol y playa (resorts de grandes cadenas internacionales con todo incluido, cruceros y turismo residencial inmobiliario).

El sistema turístico descubre determinados destinos relativamente vírgenes que inician actividades de turismo de aventura, naturaleza y otros, para luego masificarse, perder su novedad y decaer. Después, los capitales se van a otros destinos «por descubrir» (Cañada 2010: 15), dejando a su paso una especulación feroz y una apropiación de tierras y recursos a los cuales no van a poder acceder los antiguos propietarios (o, como mucho, a sus migajas), muchos de ellos indígenas y campesinos.

En la misma línea, un trabajo sobre el turismo en Jamaica de Polly Pattullo (1996) describe el dominio histórico de los intereses del capital estadounidense, primero con la explotación de bananas, a través de la United Fruit Company, y luego con el control del turismo. El control del turismo, escribe este autor, se produjo a través de un proceso que define como integración vertical, es decir, los turoperadores estadounidenses eligen los vuelos, los hoteles, el transporte interno y las visitas. Al trabajar con grandes volúmenes de visitantes, negocian con más poder frente a las compañías aéreas, organizan vuelos chárter, reservan hoteles y presionan para reducir los precios del alojamiento.

En Cancún, región de Quintana Roo (México), el desarrollo turístico implicó la pérdida de características de la población de origen maya, la pérdida de su idioma, su modo de vestir y su espacio. Además, el turismo acabó por desplazar al $65 \%$ de la población maya (Arnaizburne 1996), destruir la propiedad comunal de las tierras y consolidar la propiedad privada y las desigualdades acentuadas por una cultura consumista (Pi-Sunyer et al. 2001).

En el lago Titicaca el turismo de la isla de Taquile ha revitalizado la artesanía textil y la identidad comunitaria beneficiando a todos, pero en la isla de Amantani del mismo lago Titicaca, los quechuas controlan los medios de producción turística, que son las lanchas para pasear en el lago a los turistas, pero al mismo tiempo, en Amantani 
se ha producido una desigualdad en la estructura social asociada a conflictos entre los beneficiarios y los excluidos del desarrollo turístico (Gascón Gutiérrez 2005).

En la zona indígena chilena de Atacama, los turistas dejan poco dinero, ya que los tours se contratan a empresas de Santiago de Chile y Calama, de capital extranjero (Anta 2007: 158).

El trabajo de Elisabeth Kirtsoglou y Dimitrios Theodossoupoulos (2004) sobre los garífuna de Roatán (Honduras) pone de manifiesto cómo los garífuna valoran el turismo, pero éste es explotado por otros. Según los autores citados, los garífuna no buscan solamente desarrollo económico con el turismo, sino también reconocimiento de su propiedad cultural y de su autoridad para presentarse a sí mismos a los turistas, sin la mediación de otros agentes externos. Roatán es una zona que recibe unos cien mil visitantes al año, fundamentalmente estadounidenses, que vienen en crucero y en avión. Los garífuna piensan que ellos se benefician poco del turismo y están interesados en controlar las ganancias económicas, pero también los significados de su cultura.

$\mathrm{Y}$ en el caso de los raramuri (tarahumara) de Bacajipare, en la provincia mexicana de Chihuahua, los indígenas han recibido disparos y amenazas de muerte en un conflicto por la explotación turística del parque Divisadero Barrancas que pretende gestionar un grupo de capital español. Los indígenas se oponen a este proyecto y optan por su autodeterminación y control de los recursos naturales y culturales ${ }^{6}$, en vez de quedar como jardineros o empleados marginales de los hoteles con bajos salarios (Muqbil 2009: 5).

\subsection{La visión adaptativa del turismo indígena}

La tercera perspectiva de la que hablamos al inicio de este apartado adopta una mirada reflexiva al turismo (Pérez Galán 2006, 2011), pero es capaz de valorar sus múltiples caras y considerar que, si bien el turismo puede traer impactos negativos, también hace que las comunidades se readapten de forma creativa (Mowforth et al. 2008).

Un ejemplo de esta tercera perspectiva analítica es el trabajo de Grünewald (2001). Este autor brasileño ha trabajado con los indígenas pataxó del Noreste de Brasil, quienes han desarrollado un turismo que les ha dado un estatus diferenciado y una nueva producción cultural instrumental. Ellos se han mostrado creativos e inventivos con su cultura a partir de la selección de varios orígenes, algo que también apunta el documental de Peter Anton Zoettl (2010) sobre los pataxó de la comunidad de Coroa Vermelha.

Nuestro propio trabajo sobre el turismo indígena kuna (Pereiro y De León 2007; Pereiro et al. 2012) en Panamá ilustra cómo el turismo es un arma de doble filo que tiene diferentes efectos, pero que si es controlado políticamente por el grupo indígena puede generar una mejor y mayor distribución de sus beneficios, una disminución o paliación de los efectos negativos, una adaptación creativa a las relaciones localglobal y una afirmación étnica positiva en la perspectiva de los kunas. De esta forma,

6 Ver también http://ww4report.com/node/6684 
el cuasi monopolio del desarrollo turístico protagonizado por los kunas es parte de su estrategia de supervivencia y adaptación cultural. Lejos de ser pasivos e indiferentes, los kunas utilizan el turismo como un instrumento para alcanzar objetivos económicos (disminuir la pobreza), políticos (reivindicar sus tierras, mares y territorios), ambientales (conservar su medioambiente) y socioculturales (aumentar sus derechos culturales y su autoestima colectiva).

Desde esta óptica, y de acuerdo con Lisa Mastny (2003: 46-51), dos son las alternativas que las formas turísticas pueden plantear como turismo indígena. La primera es la participación local en el turismo, que puede reducir la fuga de ingresos, aumentar el respeto local por sus recursos y promover la conservación del medio ambiente. $\mathrm{La}$ segunda alternativa es el turismo sostenible, que es aquel que tiene como fin lograr la gestión de todos los recursos de modo que satisfaga las necesidades humanas respetando la integridad cultural, los procesos ecológicos esenciales y la diversidad biológica. Más que cualquier otra actividad, el turismo depende de un medio ambiente limpio.

Desde esta perspectiva podemos afirmar que el turismo indígena, más que un simple producto o derivado del turismo cultural para diversificar la oferta del sistema turístico, podría plantearse como una forma alternativa de hacer un turismo más reflexivo, ético y educativo. Pero ello será posible siempre que se haga de una forma planeada (Butler y Hinch 1996) y también autocontrolada en su velocidad, forma, recursos y apoderamiento de los propios indígenas. Es lo que algunos autores denominan turismo con responsabilidad social, turismo de base comunitaria y viajes a la conciencia (Rodríguez 2011: 10) que eviten la zooificación de los indígenas (Mowforth et al. 2008: 143).

\section{Conclusiones}

La antropología del turismo ha incidido de forma destacada en los efectos del turismo sobre las comunidades receptoras y en menor medida en los países emisores, los turistas o los mediadores. Esto es positivo, pero al mismo tiempo crítico desde una aproximación sistémica al turismo.

Y si nos fijamos en la literatura sobre los efectos del turismo, hay que contextualizarla en la relación problemática entre turismo y desarrollo, como hicimos más arriba, derivando los debates actuales hacia una visión más limitada de los efectos del turismo, no considerando éste como el único motor de cambios, ni muchas veces el más importante, y no convirtiéndolo siempre en un elemento estructurador o situacional del cambio.

La literatura internacional sobre el turismo indígena se enriquece en su diversidad si prestamos más atención al contexto latinoamericano y a sus perspectivas en lengua española y portuguesa. Ha sido así como hemos analizado tres perspectivas del turismo indígena en América Latina: la optimista, la pesimista y la adaptativa. Estas coinciden básicamente con las plataformas del conocimiento científico del turismo de las que nos habla Jafar Jafari $(2001,2005)$ y en la actualidad conviven bajo modelos de análisis e intervención diferentes. 
La primera se acerca más al apoderamiento de los grupos indígenas desde una perspectiva feliz del turismo, pareciendo ver solamente un lado del desarrollo turístico. Esta perspectiva beneficia y legitima la mercantilización del turismo indígena.

La segunda perspectiva es la del descontento con el turismo y alerta sobre los impactos negativos del turismo sobre las comunidades indígenas latinoamericanas, al mismo tiempo que cuestiona sus pocos o nulos beneficios para los indígenas, siendo la mayoría de ellos para los países emisores y las empresas intermediarias. Esta otra cara de la moneda es una llamada de atención a la observación crítica con el turismo, que defiende modelos alternativos del turismo (ej. turismo comunitario, justo, responsable, ético...) que no sean simplemente un maquillaje o una estrategia de marketing.

Finalmente, la tercera perspectiva se basa en una posición reflexiva para superar la anterior dualidad dicotómica, y evalúa los efectos positivos y negativos según los contextos y la casuística. En su propuesta y análisis defiende la necesidad de más política, participación y control indígena del desarrollo turístico siguiendo principios que beneficien lo máximo posible a los indígenas, pero sin olvidar el derecho indígena a decir no al turismo y a controlar sus recursos naturales y culturales, tan apetecidos por el turismo depredador. Desde esta perspectiva, los beneficios nativos parecen ser mayores cuando ellos mismos manejan y controlan directamente el desarrollo turístico (Chambers 2000).

$\mathrm{Si}$ atendemos a la gran diversidad de casos de estudio, vemos cómo las perspectivas no son unánimes a la hora de interpretar el desarrollo turístico y sus beneficios o perjuicios sobre las comunidades indígenas receptoras. Pero en líneas generales, son mayoritarias las críticas en los casos en que se analizan modelos de turismo masivo y agresivo con la cultura y el medio ambiente. Y son más optimistas cuando los modelos de desarrollo turístico son participativos, comunitarios y responsables. Sin embargo, hay que llamar la atención sobre la dificultad de definir con precisión el concepto de turismo responsable (Gascón 2011), considerarlo como un movimiento social altermundista y cuestionar algunos modelos de turismo agresivo que se disfrazan con discursos de turismo responsable y comunitario sin llegar a serlo, por lo que debemos adoptar una visión crítica frente a ello.

Agradecimientos: Este texto se encuadra en el proyecto de investigación del CETRAD titulado «Estudio estratégico del turismo en Kuna Yala (Panamá)» y que ha sido financiado por la SENACYT (Secretaría Nacional de Ciencia y Tecnología) de la República de Panamá (código contrato: CID07-009). El informe final del proyecto ha sido premiado con el VIII Premio Internacional de Estudios turísticos Gabriel Escarrer. Agradezco a la antropóloga Beatriz Pérez Galán (UNED) y al lingüista José Manuel Giménez (UTAD) sus comentarios sobre la versión preliminar de este texto.

\section{Referencias bibliográficas}

ANTA, José Luis

2007 «Desarrollo y turismo en Atacama (Chile). De la precariedad a la necesidad», en Antropología y turismo. Claves culturales y disciplinares, David Lagunas, ed., pp. 153-163. México: Plaza y Valdés. 
Arnaizburne, Stele M.

1996 «Desarrollo turístico y medioambiente en el Caribe Continental». Estudios y Perspectivas en Turismo 5 (2): 259-286.

Athias Monteiro, Renato

2008 «Índios, eco-turismo e desenvolvimento no noroeste amazônico», en Turismo, Cultura y Desarrollo, Angel Espina Barrio, ed., pp. 303-314. Salamanca: Diputación de Salamanca.

BARRETTO, Margarita

2005 «Turismo étnico y tradiciones inventadas», en El encuentro del turismo con el patrimonio cultural: concepciones teóricas y modelos de aplicación, Agustín Santana y Llorenç Prats, ed., pp. 39-56. Sevilla. FAAEE- Fundación El Monte.

2007 Turismo y Cultura. Relaciones, contradicciones y expectativas. Tenerife: Pasos. Documento electrónico, <http://www.pasosonline.org/Paginas/e-book_1.htm>, con acceso el 24/4/2013.

BARTH, Frederick

1969 Ethnic Groups and Boundaries. Londres: Allen and Unwin.

2003 «Temáticas Permanente e Emergentes na Análise da Etnicidade», en Antropologia da etnicidade. Para além de 'Ethnic Groups and Boundaries', Hans Vermeulens y Cora Govers, eds., pp. 19-44. Lisboa: Fim de Século.

BLANGY, Sylvie

1999 «O despegue do ecoturismo». O Correo da Unesco (agosto-septiembre 1999): 32-33.

Boissevain, Jeremy, ed.

1996 Coping with Tourists: European Reactions to Mass Tourism. Providence-Oxford: Berghahn Books.

BoISSEVAIN, Jeremy

2005 «Rituales ocultos. Protegiendo la cultura de la mirada turística». Pasos. Revista de Turismo y Patrimonio Cultural 3 (2): 217-228.

BRUNER, Edward M.

1995 «The Ethnographer/Tourist in Indonesia», en International Tourism. Identity and Change, Marie-Françoise Lanfant, John B. Allcock, y Edward M. Bruner, ed., pp. 224-241. Londres: Sage.

BuADES, Joan

2006 Exportando paraísos. La colonización turística del planeta. Palma de Mallorca: Ediciones La Lucerna.

ButLer, Richard y Thomas Hinch, eds.

1996 Tourism and Indigenous Peoples. Londres: Thompson.

CANadian Tourism Commission, ed.

1997 Aboriginal Tourism: A Bibliography. Tourism Reference and Documentation Centre. Ottawa: Canadian Tourism Commission.

CANestrini, Duccio

2009 No disparen contra el turista. Un análisis del turismo como colonización. Barcelona: Ediciones Bellaterra. 
CAÑADA, Ernest

2010 Impactos del turismo en los paises del sur y turismo rural comunitario. Material de apoyo. Madrid: Foro Turismo Responsable.

CAVAco, Carminda

2009 «Turismo Étnico. Um nicho de mercado temático?», en Turismos de nicho. Motivações, produtos, territórios, José Manuel Simões y Carlos Cardoso Ferreira, eds., pp. 233-261. Lisboa: Centro de Estudos Geográficos.

Chambers, Erve

2000 Native Tours: The Anthropology of Travel and Tourism. Prospect Heights: Waveland Press.

Chernela, Janet M.

2011 «Barrier Natural and Unnatural: Islamiento as a Central Metaphor in Kuna Ecotourism». Bulletin of Latin American Research 30 (1): 35-49.

COHEn, Erik

1988 «Authenticity and Commoditisation in Tourism». Annals of Tourism Research 15: 371-386.

Comaroff, John y Jean ComarofF

1992 Ethnography and the Historical Imagination. Boulder: Westview Press.

Costa, Francisco Lima

2006 «Turismo étnico, cidades e identidades: o Projecto 'Sabura - África, aqui tão perto!'. Uma viragem cognitiva na apreciação da diferença». Revista Turismo \& Desenvolvimento 5: 95-112.

DE KADT, Emanuel, ed.

1979 Turismo: ¿Pasaporte al desarrollo? Madrid: Endymion.

EsPinOsA, María

2010 «Turismo comunitario en Saraguro - Ecuador», en Turismo y desarrollo: experiencias desde la cooperación internacional, pp. 65-117. Madrid: Sodepaz.

FAlConí, Fander y Juan PONCE

2007 Desarrollo social y económico de la Amazonía Ecuatoriana basado en el ecoturismo: emprendimientos populares como alternativa a un desarrollo excluyente. Palma de Mallorca: Fundació Càtedra Iberoamericana - Universidad de las Islas Baleares. Documento electrónico, <http://fci.uib.es/Servicios/libros/investigacion/falconi/>, con acceso el 24/4/2013.

GASCÓN, Jordi

2009 El turismo en la cooperación internacional. Barcelona: Icaria.

2011 «El turismo responsable». Chaves: UTAD (texto inédito de conferencia pronunciada el 25-05-2011).

GASCÓN, Jordi y Ernest CAÑADA

2005 Viajar a todo tren: turismo, desarrollo y sostenibilidad. Barcelona: Icaria.

GASCÓN GuTIÉRREZ, Jorge

2005 Gringos como en sueños. Diferenciación y conflicto campesino en el sur andino peruano ante el desarrollo del turismo. Lima: Instituto de Estudios Peruanos. 
Getino, Octavio

1991 Turismo y desarrollo en América Latina. México: Editorial Limusa.

GMELCH, George

2003 Behind the Smile. The Working Lives of Caribbean Tourism. Bloomington: Indiana University Press.

GreEnwood, Davydd J.

1992 «La cultura al peso: perspectiva antropológica del turismo en tanto proceso de mercantilización cultural», en Anfitriones e invitados, Valene L. Smith, ed, pp. 257-279. Madrid: Endymion.

GRÜNEWALD, Rodrigo de Azeredo

2001 «Turismo e o 'resgate' da cultura Pataxó», en Turismo e identidade local: uma visão antropológica, Alvaro Banducci Junior y Margarita Barretto, ed., pp. 127148. Campinas: Papirus.

2003 «Turismo e etnicidade». Horizontes Antropológicos 20: 141-159.

Hall, C. Michael, Allan M. Williams y Alan A. Lew

2007 «Turismo: conceitos, instituições e temas», en Compêndio de turismo, Michael C. Hall, Allan M. Williams y Alan A. Lew, eds., pp. 23-41. Lisboa: Instituto Piaget

HARron, Sylvia y Betty WeILER

1992 «Review. Ethnic Tourism», en Special Interest Tourism, Betty Weiler y Chris M. Hall, ed., pp. 83-92. Londres: Bellhaven.

HARRISON, Julia

2003 Being a Tourist. Vancouver: University of British Columbia Press.

HERNÁNDEZ RAMíREZ, Javier

2006 «Producción de singularidades y mercado global. El estudio antropológico del turismo». Boletín Antropológico 66: 21-50.

INGLES, Palma

2002 «Welcome to May Village: Hosting Tourists in the Peruvian Amazon». Tourism Recreation Research 27 (1): 53-60.

JAFARI, Jafar

2001 «Toward and Ethics Platform for Tourism». Annals of Tourism Research 32 (4): 962-984.

2005 «El turismo como disciplina científica». Política y Sociedad 42 (1): 39-56.

Johnston, Alison M.

2006 Is the Sacred for Sale? Tourism and Indigenous Peoples. Londres: Earthscan.

KiRTSOglou, Elisabeth y Dimitrios Theodossopoulos

2004 «They are Taking Our Culture Away: Tourism and Culture Commodification in the Garifuna Community of Roatan». Critique of Anthropology 24 (2): 135-157.

KutZner, Diana, Patrick T. MAher y Pamela Wright

2007 Aboriginal Tourism: A Research Bibliography. Prince George (Canadá): University of Northern British Columbia: Outdoor and Tourism Management Programme. Documento electrónico, <http://www.unbc.ca/assets/ortm/research/report_2007_02_aboriginal_tourism_bibliography.pdf $>$, con acceso el 7-04-2010. 
MaCCANELL, Donald

1984 «Reconstructed Ethnicity: Tourism and Cultural Identity in Third World Communities». Annals of Tourism Research 11 (3): 375-391.

1992 Empty Meeting Grounds. Nueva York: Routledge and Kegan Paul.

Maldonado, Carlos

2006 Turismo y comunidades indígenas: Impactos, pautas para autoevaluación y códigos de conducta. Documento de trabajo número 79. Ginebra: Oficina Internacional del Trabajo.

Mastny, Lisa

2003 Ecoturismo. Nuevos caminos para el turismo internacional. Bilbao: Bakeaz.

MERCER, David

1995 «Native People and Tourism: Conflict and Compromise», en Global Tourism The Next Decade, William F. Theobald, ed., pp. 124-145. Oxford: ButterworthHeinnemann.

Morales, Guillermo y Daniel Marías

2007 «Turismo en comunidades indígenas». Revista Ábaco (2ª́poca) 54: 123-133.

Moscardo, Gianna y Philip L. Pearce

1999 «Interpretación del turismo étnico». Annals of Tourism Research en Español 1: 147-166.

Mowforth, Martin, Clive Charlton e Ian Munt

2008 Tourism and Responsibility: Perspectives from Latin American and the Caribbean. Londres: Routledge.

MuQBIL, Imtiaz

2009 Turismo indígena: Mucho más que otro mercado más. Berlín: ITB. Documento electrónico, <http://www.itb-kongress.de/media/itbk/itbk_media/itbk_image/ itbk_apps/itbk_dlc/ITB_turismo_indigena.pdf>, con acceso el $24 / 4 / 2013$.

NASH, Dennison

1992 «El turismo considerado como una forma de imperialismo», en Anfitriones e invitados. Antropología del turismo, Valene Smith, ed., pp. 69-91. Madrid: Endymion.

OAKES, Tim

2000 «Ethnic Tourism», en Encyclopaedia of Tourism, Jafar Jafari, ed., pp. 204-206. Londres: Routledge.

Organización Mundial del Turismo

2003 Turismo internacional: uma perspectiva global. Porto Alegre: Bookman.

O'Rourke, Dennis

1988 Cannibal Tours. Documental producido por Dennis O'Rourke.

Pattullo, Polly

1996 Last Resorts. The Cost of Tourism in the Caribbean. Londres: Cassel.

Pereiro Pérez, Xerardo

2009 Turismo cultural. Uma visão antropológica. La Laguna: Pasos. Documento electrónico, <http://www.pasosonline.org/Paginas/e-book_2.htm>, con acceso el 24/4/2013.

Pereiro Pérez, Xerardo y Cebaldo De León InAwinapi

2007 Los impactos del turismo en Kuna Yala. Turismo y cultura entre los kuna de Panamá. Madrid: Editorial Ramón Areces. 
Pereiro Pérez, Xerardo, Cebaldo De León, Mónica Martínez, Jorge Ventocilla y Yadixa Del Valle

2012 Los turistores kunas. Antropología del turismo étnico en Panamá. Palma de Mallorca: Universitat de les Illes Balears.

PÉREZ GALÁN, Beatriz

2006 «Turismo y representación de la cultura: identidad cultural y resistencia en comunidades del Cusco». Anthropologica 24: 29-49.

2011 «Nuevas y viejas narrativas turísticas sobre la cultura indígena en los Andes», en Turismo y patrimonio. Entramados narrativos, Llorenç Prats y Agustín Santana, eds., pp. 27-48. La Laguna: Pasos. Documento electrónico, <http://www.pasosonline.org/Paginas/e-book_5.htm>, con acceso el 24/4/2013.

PICARD, Michel y Robert E. Wood, eds.

1997 Tourism, Ethnicity and the State in Asian and Pacific Societies. University of Hawai'i Press.

Pi-Sunyer, Oriol, R. Brooke Thomas y Magalí Daltabuit

2001 «Tourism on the Maya Periphery», en Hosts and Guests Revisited: Tourism Issues of the 21st Century, Valene Smith y Maryann Brent, eds., pp. 122-140. Nueva York: Cognizant.

PitchFormd, Susan R.

1995 «Ethnic Tourism and Nationalism in Wales». Annals of Tourism Research 22: 3552.

Prats, Llorenç y Agustín Santana, eds.

2011 Turismo y patrimonio. Entramados narrativos. La Laguna: Pasos. Documento electrónico, <http://www.pasosonline.org/Paginas/e-book_5.htm>, con acceso el 24/4/2013.

RichARDS, Greg

1996 «Introduction: Culture and Tourism in Europe», en Cultural Tourism in Europe, Greg Richards, ed., pp. 3-17. Oxon: CAB International.

Rodríguez Miranda, Rodrigo, ed.

2011 Construyendo resistencias. Experiencias de turismo local. Madrid: Foro Turismo Responsable.

Rosaldo, Renato

1989 Cultura y Verdad. Nueva propuesta de análisis social. México: Grijalbo.

RYAN, Chris

2005a «Introduction. Tourist-Host Nexus. Research Considerations», en Indigenous Tourism: The Commodification and Management of Culture, Chris Ryan y Michel Aicken, eds., pp. 1-15. Oxford: Elsevier.

2005b «Who Manages Indigenous Cultural Tourism Product - Aspiration and Legitimation», en Indigenous Tourism: The Commodification and Management of Culture, Chris Ryan y Michel Aicken, eds., pp. 69-74. Oxford: Elsevier.

RyAn, Chris y Michel Aicken, eds.

2005 Indigenous Tourism: The Commodification and Management of Culture. Oxford: Elsevier. 
Ryan, Chris y Jeremy Huyton

2005 «Balanda Tourists and Aboriginal People», en Indigenous Tourism: The Commodification and Management of Culture, Chris Ryan y Michel Aicken, eds., pp. 5168. Oxford: Elsevier.

SAlazar, Noel B.

2006 «Antropología del turismo en países en desarrollo: análisis crítico de las culturas, poderes e identidades generados por el turismo». Tabula Rasa 5: 99-128.

Santana, Agustín

1997 Antropología y Turismo. ¿Nuevas Hordas, Viejas Culturas? Barcelona: Ariel.

SMith, Valene L.

1996 «Indigenous Tourism: The Four Hs», en Tourism and Indigenous Peoples, Richard Buter y Thomas Hinch, ed., pp. 283-307. Londres: Thomson.

Sмith, Valene L., ed.

1977 Hosts and Guests: The Anthropology of Tourism. Filadelfia: University of Pennsylvania Press.

1989 Hosts and Guests: The Anthropology of Tourism, $2^{\mathrm{a}}$ ed. Filadelfia: University of Pennsylvania Press.

1992 Anfitriones e invitados. Antropología del turismo. Madrid: Endymion.

Sмith, Valene L. y William R. EAdington, eds.

1992 Tourism Alternatives: Potentials and Problems in the Development of Tourism. Filadelfia: University of Pennsylvania Press.

VAN DEN BERGHE, Pierre

1980 «Tourism as Ethnic Relations: A Case Study of Cuzco, Peru». Ethnic and Racial Studies 3 (4): 375-391.

1994a The Quest for the Other: Ethnic Tourism in San Cristobal México. Seattle: University of Washington Press.

1994b «Marketing Mayas: Ethnic Tourism Promotion in Mexico». Annals of Tourism Research 22 (3): 568-588.

Vermeulen, Hans y Cora Govers, eds.

2003 Antropologia da etnicidade. Para além de 'Ethnic Groups and Boundaries'. Lisboa: Fim de Século.

VIGNA, Anne

2006 «Los 'falsarios' del ecoturismo: Grandes proyectos privados en América Central». Le Monde Diplomatique (julio 2006).

Volkman, Toby A.

1990 «Visions and Revisions: Toraja Culture and the Tourist Gaze». American Ethnologist 17 (1): 91-110.

ZEPPEL, Heather

2007 «Indigenous Ecotourism: Conservation and Resources Rights», en Critical Issues in Ecotourism. Understanding a Complex Tourism Phenomenon, James Higham, ed., pp. 308-348. Oxford: Elsevier.

ZoettL, Peter Anton

2010 Capa de índio. Documental antropológico. 